\title{
A Personal Retrospective on the Origin of the Time-of-Flight Atom Probe
}

\author{
Douglas F. Barofsky ${ }^{1}$ \\ ${ }^{1 .}$ Department of Chemistry, Oregon State University, Corvallis, Oregon.
}

Who created the atom probe microscope? By virtue of being listed as the sole inventor on a patent issued in 1971 and bearing the title "Atom Probe Field Ion Microscope Having Means for Separating the Ions According to Mass" [1], the immediate and simple answer to this question must be Erwin W. Müller (Mueller). As my title suggests however, I am going to make a case in this paper for a more expansive answer. It was my good fortune to play a seminal role in the genesis of the atom probe microscope. From the vantage of that experience, I maintain that the atom probe microscope and, in particular, the time-of-flight (ToF) atom probe microscope emerged from a synthesis of advances in ToF mass spectrometry (MS), the advent and development of field-ion microscopy (FIM), and early attempts to apply MS to the study of field ionization.

Speaking at a meeting of the American Physical Society held at Massachusetts Institute of Technology in 1946, Stephens [2] gave a very succinct description of a ToF mass spectrometer and, by doing so, set in motion the series of sporadic instrumental advances, among which was the introduction in 1961 of the Bendix Model 306 Magnetic Electron Multiplier [3], a device that was to play a crucial role in the success of the atom probe's immediate forerunner. In 1951, Müller described his invention of FIM and its improved resolution compared with field-electron microscopy [4]. In 1954, Inghram and Gomer reported the first ever mass spectra of field-ionized atoms using a field-ion source coupled to a 60-degree, magnetic-sector mass spectrometer [5]. On 11 October 1955, Müller and his student Kanwar Bahadur achieved full atomic resolution of the surface structure of a metal [6,7]. The following year, Müller clearly described room temperature field evaporation of $\mathrm{W}[8]$.

I was privileged to join Müller's Field Emission Laboratory at Penn State in the Fall of 1963. Over the course of the next year and a half, I designed and constructed a multiple, first-order focusing mass spectrometer with a field ionization source [9]. Regrettably, attempts to detect field evaporated atoms and field-induced chemical reaction products with this instrument met with failure due to insufficient detection sensitivity. By the middle of my second year in the Field Emission Lab, I had learned of the Bendix 306 multiplier [3]. Upon complete of my Master's thesis, Müller purchase one, and I installed it in my mass spectrometer. This modification almost instantly made it possible to detect field evaporated ions under the normal, low temperature, operating conditions of a field-ion microscope [10]. Presumably as a result of this very quick success, Müller began to discuss with me the possibility of performing mass spectrometric analysis on single, field-desorbed atom sometime near the end of 1965 or beginning of 1966. He envisioned field evaporating a single atom identified in a field-ion image through an aperture into a mass analyzer. I do not know when this idea first occurred to him, but it was unquestionably his. On and off during the first half of 1966, we discussed various ways by which my instrument or one similar to it might be used to detect and identify field-evaporated atoms and field-desorbed molecular species one at time. Clearly, single-particle detection had become feasible, but how to configure the device's ion source and mass analyzer remained an open question. Müller conceived the name "Atom Probe" for the device after meeting Raimond Castaing, father" of electron microprobe analysis [11], during the course of a trip to Europe that summer. In the fall of 1966, I took a graduate course in mass spectrometry and learned about ToF MS. After making a few back-of-envelope calculations, I quickly 
became persuaded that a time-of-flight tube would be the ideal mass analyzer for the atom probe. I suggested this to Müller, and he asked me to work up preliminary dimensions and operating characteristics for a ToF atom probe based on timing electronics available at that time.

Around April 1967, Müller and I began drafting a patent application. He wrote descriptions for field-ion sources with probe holes, I crafted descriptions for mass analyzers including a ToF analyzer. The magnetic mass analyzers we considered were modeled on the instrument I built for my thesis research, and the ToF analyzer, which was nothing more than a drift tube and a detector, was based on my feasibility calculations. A couple of weeks or so prior to submitting the application, Müller pronounced that he was submitting it as sole inventor. He rationalized this action on the grounds that the essence of the invention was his concept for the atom-probe field-ion microscope, which was his alone, and that its various embodiments, which we had co-written, represented only a small subset of all the possible ways in which the concept might be implemented.

Although I was disappointed by Müller's conduct, it was characteristic of him, and I was not surprised by it when he imposed it on me in this instance. I had by my second year in the Field Emission Lab observed that Müller regarded those of his former students, who after leaving Penn State elected to remain active in areas of research that overlapped with his interests, as competitors and that his relationship with them became somewhat confrontational. Partly in consequence of this aspect of Müller's character, I had long since decided to strike out on new scientific course after I graduated. By the time he and I were drafting the atom probe patent application, I had become intrigued with the research being reported by the likes of Klaus Biemann at MIT and Fred McLafferty then at Purdue University, both of whom were at that point in time spearheading the application of MS to the analysis of biological molecules. In May of 1968, I attended the 16th Annual Conference on Mass Spectrometry and Allied Topics, ASTM Committee E14, in Pittsburgh, PA. At that meeting, I met Hans Beckey who was pioneering field ionization MS of organic molecules. He encouraged me to apply for an Alexander von Humboldt fellowship and join his laboratory at the University of Bonn in Germany.

Erwin Müller, endowed as he was with brilliant imagination and inventiveness, was an extraordinary experimental physicist by any measure. To this day, I readily acknowledge how much scientifically I gained from his exceptional tutelage. I left his laboratory at summer's end 1968 headed for Bonn and what, in retrospect over the past fifty years, was to become a scientific career in mass spectrometry that encompassed instrumental design, physical chemistry, analytical environmental chemistry, biophysics, biochemistry, and even molecular biology.

The atom-probe application Müller and I had co-written (more correctly, I had ghost co-written) was filed with the US Patent Office 20 June 1967. For reasons I never learned, Müller had to abandon that application. On 7 May 1969, he refiled a modified version of the application, and on 31 August 1971, he was awarded the first ever patent to be issued on the atom probe field ion microscope [1].

\section{References:}

[1] EW Mueller, US Patent No. 3602710 (1971).

[2] WE Stephens, Bull. Am. Phys. Soc. 21 (1946), p. 22.

[3] GW Goodrich and WC Wiley, Rev. Sci. Instrum. 32 (1961), p. 846.

[4] EW Müller, Z. Phys. 131 (1951), p. 136.

[5] MG Inghram and R Gomer, J. Chem. Phys. 22 (1954), p. 1279. 
[6] EW Müller, Ann. Mtng. of EMSA, Penn State, (1955) p. 27. (text and abstract never published). [7] AJ Melmed, Appl. Surf. Sci. 94/95 (1996), p. 17.

[8] EW Müller, Phys. Rev. 102 (1956), p. 618.

[9] DF Barofsky, Master's Thesis, The Pennsylvania State University, (1965).

[10] DF Barofsky, Ph.D. Thesis, The Pennsylvania State University, (1967).

[11] R Castaing, Ph.D. Thesis, University of Paris, (1952). 